1

2

3

4

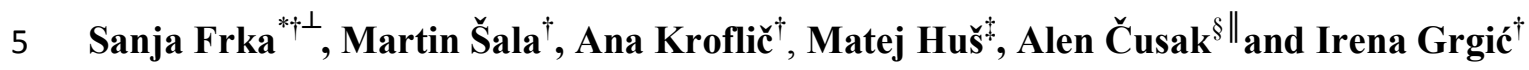

6

$7 \quad$ Analytical Chemistry Laboratory, National Institute of Chemistry, 1000 Ljubljana, Slovenia

$8 \stackrel{\perp}{ }$ Division for Marine and Environmental Research, RuđerBošković Institute, 10000 Zagreb,

9

10

11

12

13

14

15

16

17

18

19

20

21

22

23

24

\section{Quantum chemical calculations resolved identification of methylnitrocatechols in} atmospheric aerosols

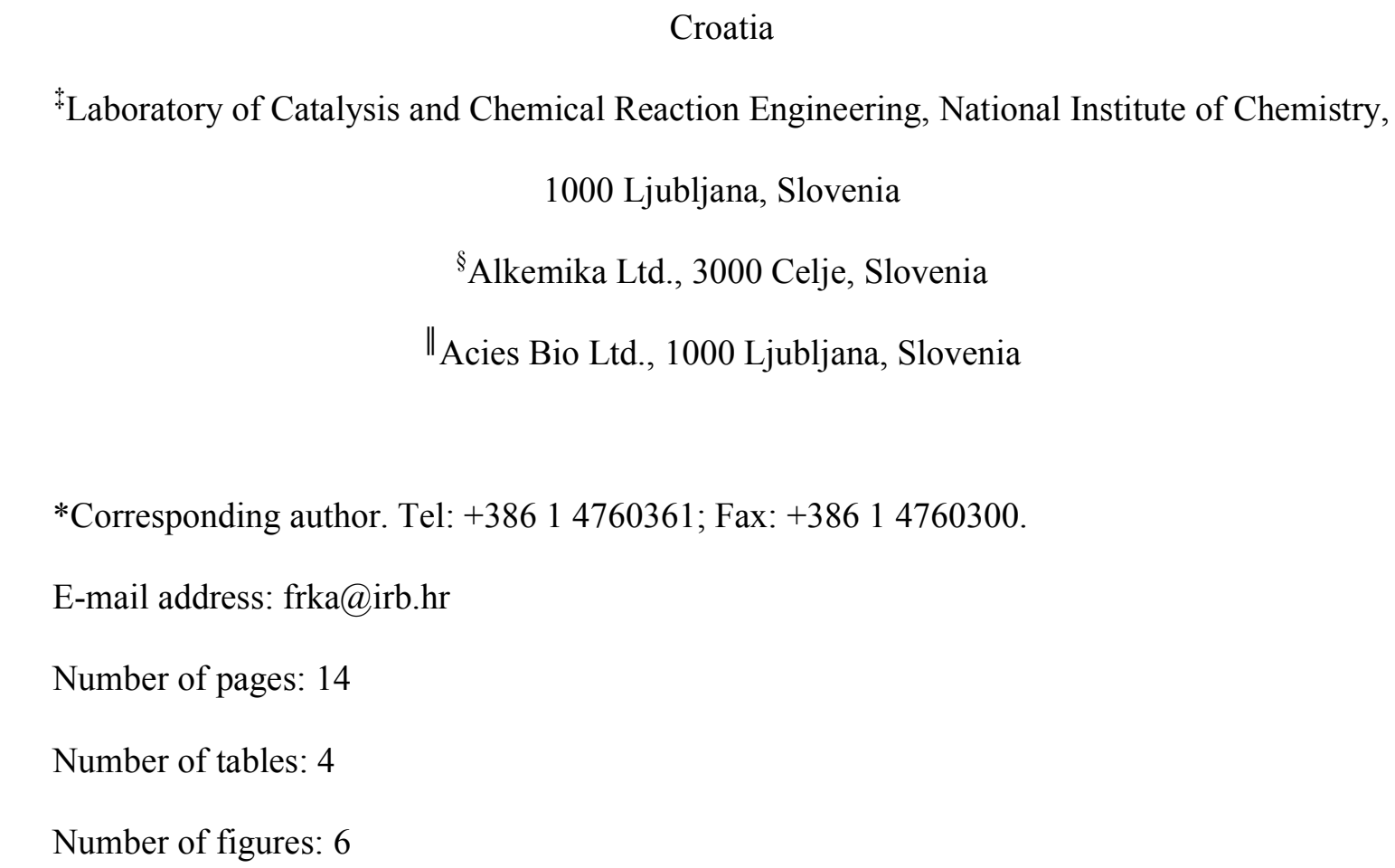




\section{Aerosol sampling and pretreatment}

During AERONAR campaign, size-segregated aerosol samples were collected on pre-baked Al-foils $\left(500{ }^{\circ} \mathrm{C}\right.$ for $24 \mathrm{~h}$ ) with Berner cascade impactor (HAUKE, LPI 25/0,015/2) at an urban background site of Ljubljana, Slovenia (approx. 270,000 inhabitants, $298 \mathrm{~m}$ a.s.1.) for 48-72 h between December 3, 2014 and March 2, 2015. The sampler was operated at a nominal flow rate of $25.8 \mathrm{~L} \mathrm{~min}^{-1}$. The impactor has 10 impaction stages expressed in aerodynamic equivalent diameter, $D_{\mathrm{ae}}\left(\right.$ stage $1: D_{\mathrm{ae}}=0.038-0.067 \mu \mathrm{m}$; stage $2: D_{\mathrm{ae}}=0.067-$ $0.104 \mu \mathrm{m}$; stage 3: $D_{\mathrm{ae}}=0.104-0.16 \mu \mathrm{m}$, stage 4: $D_{\mathrm{ae}}=0.16-0.305 \mu \mathrm{m}$, stage 5: $D_{\mathrm{ae}}=0.305-$ $0.56 \mu \mathrm{m}$, stage 6: $D_{\mathrm{ae}}=0.56-1.01 \mu \mathrm{m}$, stage 7: $D_{\mathrm{ae}}=1.01-2.1 \mu \mathrm{m}$, stage $8: D_{\mathrm{ae}}=2.1-3.99$ $\mu \mathrm{m}$; stage 9: $D_{\mathrm{ae}}=3.99-8.6 \mu \mathrm{m}$, stage 10: $\left.D_{\mathrm{ae}}=8.6-15.6 \mu \mathrm{m}\right)$. Collected samples and filter blanks (no air was drawn through the filter) were stored at $-18^{\circ} \mathrm{C}$ prior to analysis.

Aerosol mass was determined by weighing each impaction foil before and after the sampling; prior to weighing, all foils were conditioned for at least $24 \mathrm{~h}$ at a relative humidity of $50 \pm 5 \%$ and a temperature of $20 \pm 1{ }^{\circ} \mathrm{C}$. For the purpose of this study only stages with PM of $D_{\text {ae }}$ up to 2.1 $\mu \mathrm{m}$ were further processed and represented as $\mathrm{PM}_{2}$ values obtained by summing up the corresponding deposits of impactor stages from 1 to 6 . It should be kept in mind that $\mathrm{PM}_{2.1}$ is actually provided, but to simplify the data presentation, the term $\mathrm{PM}_{2}$ is used throughout the text. In order to ensure a sufficient amount of carbonaceous material for chemical analysis, stages of 2-4 samples were combined in 7 sets, each of them representing the average of 9 to 12 winter days. Foils were extracted jointly with high purity reagent Milli-Q water (Millipore, Bedford, MA, USA) and filtrated through $0.22 \mu \mathrm{m}$ pore size filter (Supelco, USA). Water extracts were further diluted in the injection solvent to finally obtain a mixture of $50 \mu \mathrm{g} \mathrm{L} \mathrm{L}^{-1}$ picric acid (internal standard, IS; Sigma-Aldrich), $7.5 \mathrm{mM}$ ammonium formate buffer $\mathrm{pH} 3$ (ammonium formate: puriss p.a., eluent additive for LC-MS, Fluka; and formic acid: eluent 
49 additive for LC-MS, Fluka), and $200 \mu \mathrm{M}$ ethylenediaminetetraacetic acid (EDTA; 99.995\%;

50 Sigma-Aldrich) for the analysis of MNCs by LC-MS/MS.

51

52

53

54

55

56

57

58

59

60

61

62

63

64

65

66

67

68

69

70

71

72 
73 Table S1. Gradient elution program used for the analysis of methylnitrocatechols. Solvent A:

74 methanol $(\mathrm{MeOH})$, solvent $\mathrm{B}$ : tetrahydrofuran (THF), solvent $\mathrm{C}$ : $7.5 \mathrm{mM}$ aqueous ammonium 75 formate buffer, $\mathrm{pH}=3$.

76

\begin{tabular}{cccc}
\hline Time (min) & Solvent A (\%) & Solvent B (\%) & Solvent C (\%) \\
\hline 0 & 30 & 15 & 55 \\
29 & 30 & 15 & 55 \\
30 & 80 & 15 & 5 \\
39 & 80 & 15 & 5 \\
40 & 30 & 15 & 55 \\
45 & 30 & 15 & 55 \\
\hline
\end{tabular}

77

78

79

80

81

82

83

84

85

86

87

88

89

90 
91

92

\section{Nitration of 3-methylcatechol and semi-preparative HPLC isolation of reaction product}

By adopted procedure ${ }^{1,2}, 1 \mathrm{~g}$ of 3MC (98\%; Sigma-Aldrich) and sodium nitrite (ACS reagent, $\geq 97 \%$; Sigma-Aldrich) were dissolved in $50 \mathrm{~mL}$ Milli-Q water in a mass ratio $2: 3$ and the solution was immersed into an ice-water bath. At constant stirring, $50 \mu \mathrm{L}$ of concentrated sulfuric acid (analysis grade, 98\%; Merck KgaA, Darmstadt, Germany) was added drop wise. The reaction mixture was left for 30 min to complete prior to extraction with $20 \mathrm{~mL}$ dichloromethane (puriss, p.a, ACS reagent, $\geq 99.9 \%$; Sigma-Aldrich). By addition of sodium sulfate (anhydrous for synthesis; Merck), the residual water was removed from the dichloromethane extract and, after filtering, it was dried to tar residue under nitrogen flow.

An Agilent 1100 HPLC system with a quaternary pump and a UV-vis diode array detector (DAD) coupled to an analytical-scale fraction collector (FC) was used for semi-preparative purification of the reaction product extracts. The tar residue was dissolved in a methanol/water mixture $(50 / 50, \mathrm{~V} / \mathrm{V})$ and a separation of containing organic compounds was performed by using Atlantis Prep T3 column (10 x 250 mm, $5 \mu \mathrm{m}$ particle size; Waters) with Atlantis Prep T3 guard column (10 x $10 \mathrm{~mm}, 5 \mu \mathrm{m}$ particle size; Waters $)$ and $1 \%$ formic acid in methanol/0.1\% formic acid $(50 / 50, \mathrm{~V} / \mathrm{V})$ as a mobile phase. The flow rate and the column temperature were $4 \mathrm{~mL} \mathrm{~min}^{-1}$ and $30{ }^{\circ} \mathrm{C}$, respectively. Two fractions were collected between the retention times of 9.30 and $10.70 \mathrm{~min}$. Methanol was evaporated from the first fraction of the collected solutions by rotavapor at $35{ }^{\circ} \mathrm{C}$, the organic material was extracted into dichloromethane and dried with anhydrous sodium sulfate. After removing the residual water and drying the extract to constant mass on the rotavapor at $35{ }^{\circ} \mathrm{C}$, yielded yellow crystals were further analyzed by high-resolution mass spectrometry, NMR as well as by LC-MS/MS. 
Table S2. Thermodynamic and geometric properties of identified intermediates and transition states (*), at $298 \mathrm{~K}$ and 1 atm when relevant. Dihedral angle is defined between hydrogen atom, carbon atom, nitrogen atom, and oxygen atom that is closer to the hydrogen atom. Charge of the nitro group is calculated as a sum of NBO charges on nitrogen and oxygen atoms.

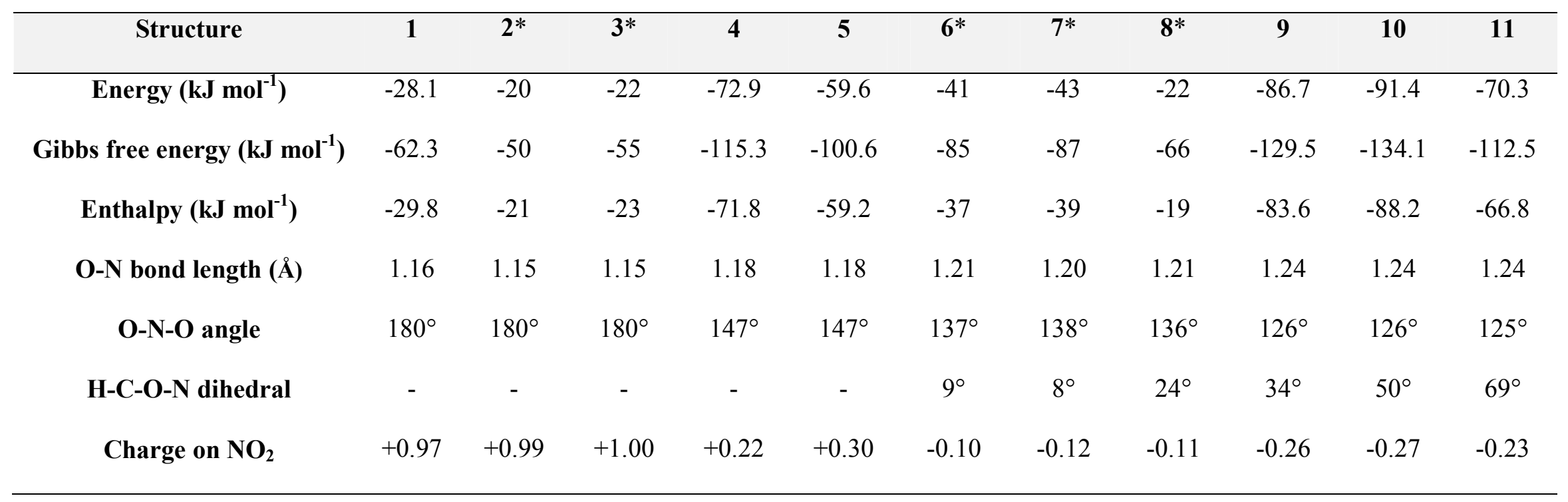




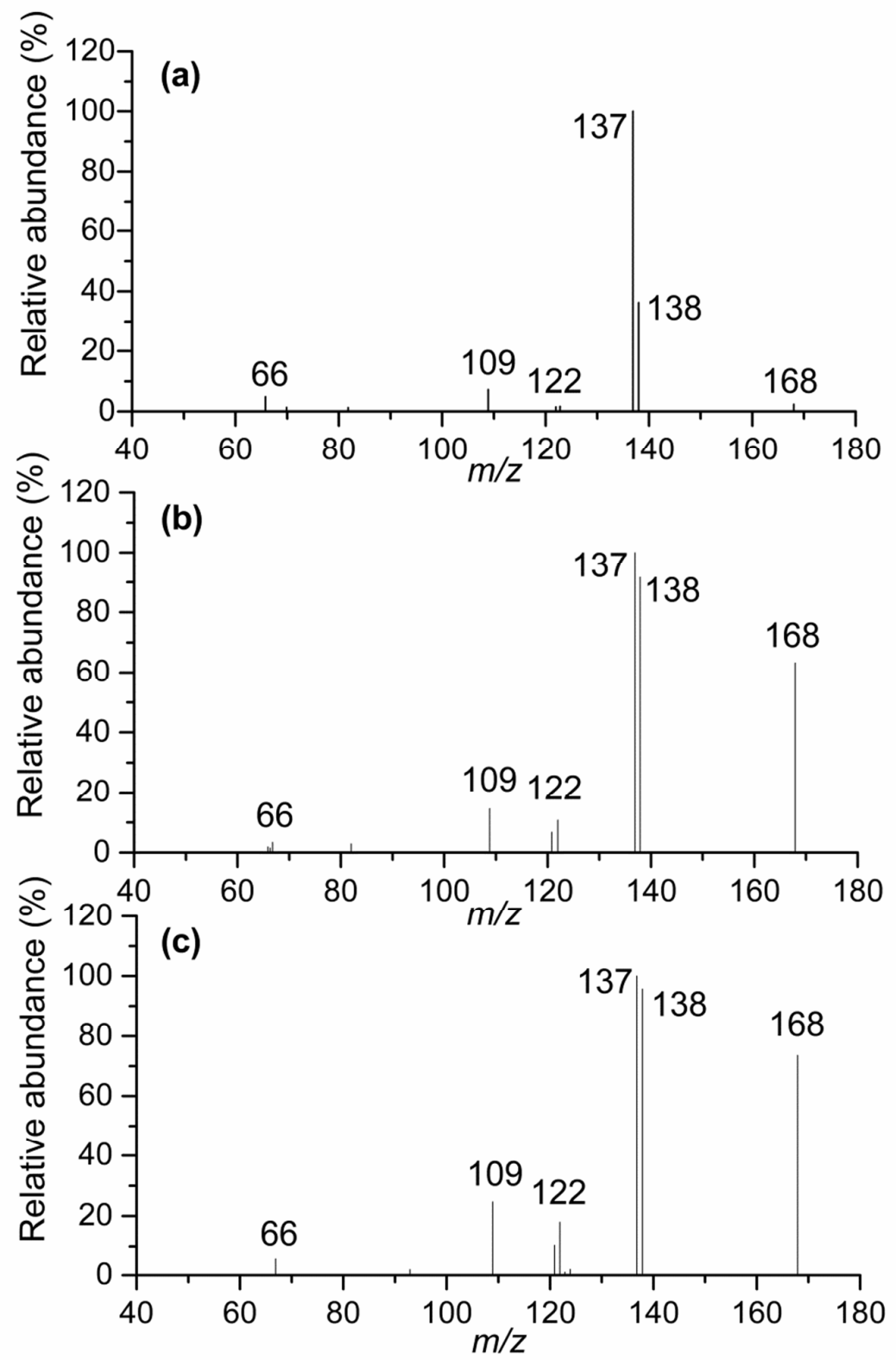

Figure S1. MS/MS fragmentation data of $\mathrm{m} / \mathrm{z} 168$ ions in ambient PM sample, Ljubljana, Slovenia (collected 14--25/1/2015) eluted at (a) $15.7 \mathrm{~min}$ and (b) $23.1 \mathrm{~min}$, and (c) the major reaction product of 3-methylcatechol nitration eluted at $23.1 \mathrm{~min}$; obtained under following conditions: MeOH:THF: water =30/15/55 (V/V/V) with $7.5 \mathrm{mM}$ ammonium formate buffer, $\mathrm{pH} 3$; flow rate $0.3 \mathrm{~mL} \mathrm{~min}^{-1}$, column temperature $30{ }^{\circ} \mathrm{C}$, injection volume $10 \mu \mathrm{l}$. Injection solvent contains $200 \mu \mathrm{M}$ EDTA. 


\section{NMR characterization of the minor reaction product after the nitration of 3-}

\section{methylcatechol}

The minor reaction product synthesized and isolated after the nitration of 3MC was structurally characterized as 3-methyl-4-nitrocatechol (3M4NC) by ${ }^{1} \mathrm{H}-\mathrm{NMR}(300 \mathrm{MHz}),{ }^{13} \mathrm{C}-$ NMR (75 MHz), and 2D correlation NMR experiments as gHSQC and gHMBC. NMR spectra were recorded in $\mathrm{CD}_{3} \mathrm{OD} .{ }^{1} \mathrm{H}-\mathrm{NMR}$ spectrum (Figure S2) displays 4 distinctive resonances as described in Table S3. Methyl group protons at C-7 display a singlet which resonates at $2.41 \mathrm{ppm}$. Both phenolic protons resonate as a broad singlet at $4.90 \mathrm{ppm}$. Aromatic proton at C-6 displays a doublet at $6.72 \mathrm{ppm}$ with a corresponding ${ }^{3} J$ coupling constant of $8.9 \mathrm{~Hz}$. Finally, the most deshielded proton in the spectrum at C-5 displays a doublet at $7.45 \mathrm{ppm}$ with a corresponding ${ }^{3} J$ coupling constant of $8.9 \mathrm{~Hz}$. The value of ${ }^{3} J$ coupling constant of $8.9 \mathrm{~Hz}$ in aromatic hydrocarbons falls within the range of orthocoupling. ${ }^{13} \mathrm{C}$-NMR spectrum (Figure S3) displayed 7 distinctive resonances. The methyl group (C-7) displays a resonance at $12.7 \mathrm{ppm}$. Furthermore, the spectrum displays 2 methine carbons which resonate at $112.4 \mathrm{ppm}(\mathrm{C}-6)$ and $118.4 \mathrm{ppm}(\mathrm{C}-5)$. Finally, 4 distinctive quaternary carbon resonances appeared at $122.7 \mathrm{ppm}(\mathrm{C}-3), 144.0 \mathrm{ppm}(\mathrm{C}-4), 145.4 \mathrm{ppm}(\mathrm{C}-$ 2) and $151.2 \mathrm{ppm}(\mathrm{C}-1)$ (Table S3). In addition, calculated ${ }^{13} \mathrm{C}-\mathrm{NMR}$ resonances are in excellent agreement with experimental values. The structural assignment of 3M4NC was further supported by gHSQC and gHMBC $2 \mathrm{D}$ correlation spectroscopy $\left({ }^{1} \mathrm{H}-{ }^{13} \mathrm{C}\right)$. Heteronuclear $\left({ }^{1} \mathrm{H}_{-}{ }^{13} \mathrm{C}\right)$ correlations from 2D-NMR experiments are presented by $2 \mathrm{D}$ contour plots shown in Figures S4 and S5. Analysis of gHSQC spectra clearly displays a correlation between H-5, H-6 and H-7 with corresponding carbon atoms C-5, C-6 and C-7 due to strong heteronuclear ${ }^{1} \mathrm{H}-{ }^{13} \mathrm{C}$ coupling (Figures S4 and S5). According to the gHMBC spectra (Figures $\mathrm{S} 4$ and S6), proton H-5 (purple labeled) displays a strong correlation with C-1 $\left({ }^{3} J\right), \mathrm{C}-3\left({ }^{3} J\right)$ and C-4 $\left({ }^{2} J\right)$ and weak correlation with C-7 $\left({ }^{4} J\right)$. Proton H-6 (blue labeled) displays a strong 
correlation with C-1 $\left({ }^{2} J\right), \mathrm{C}-2\left({ }^{3} J\right)$ and C-4 $\left({ }^{3} J\right)$ and weak correlation with C-3 $\left({ }^{4} J\right)$. Methyl group protons (H-7) display a strong correlation with C-2 $\left({ }^{3} J\right), \mathrm{C}-3\left({ }^{2} J\right)$ and $\mathrm{C}-4\left({ }^{3} J\right)$ and weak correlation with C-1 $\left({ }^{4} J\right), \mathrm{C}-5\left({ }^{4} J\right)$ and C-6 $\left({ }^{5} J\right)$. The combination of $1 \mathrm{D}$ and 2D-NMR experiments confirm that the structure of isolated nitration product corresponds to 3M4NC. 


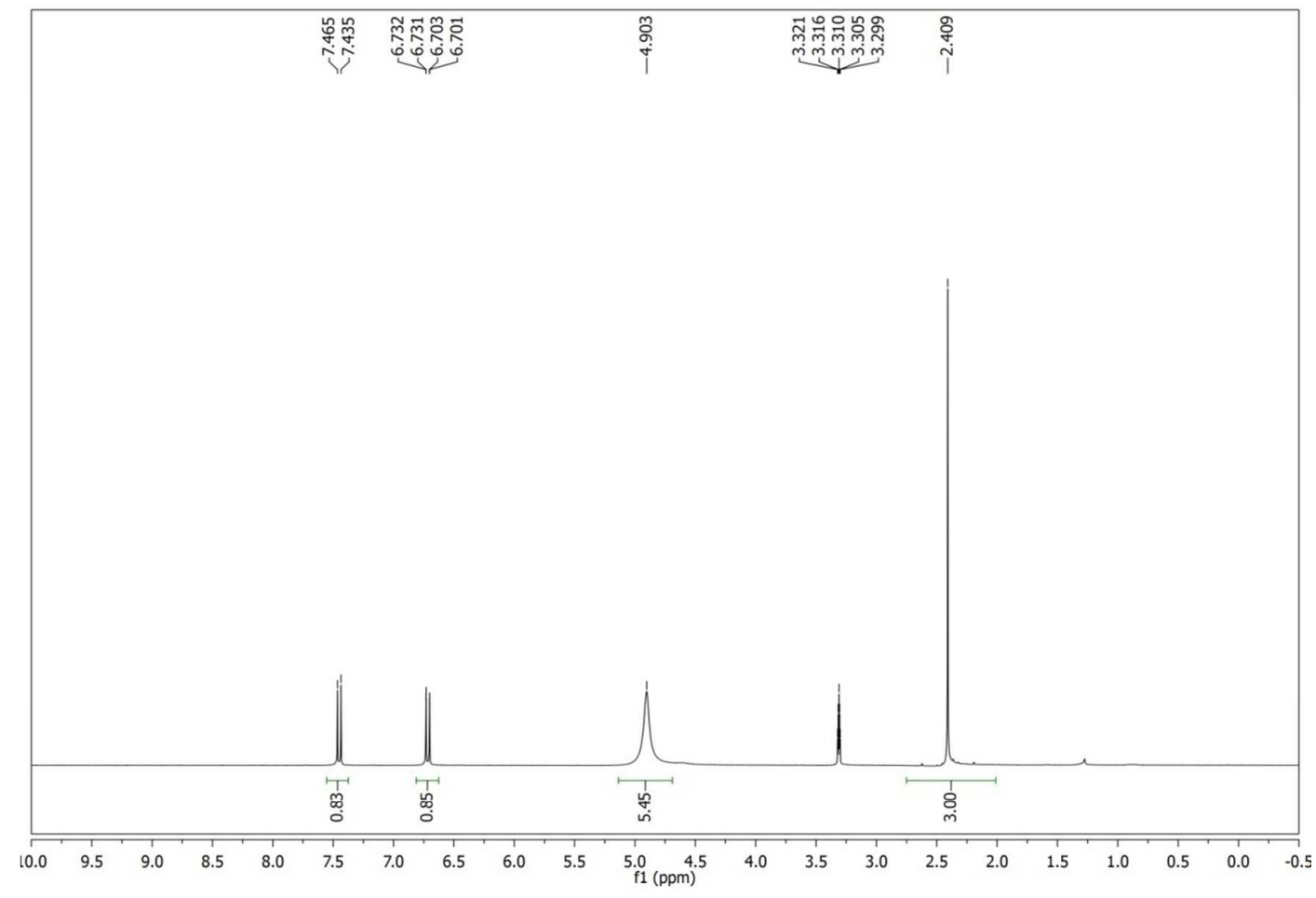

Figure S2. ${ }^{1}$ H-NMR spectrum of 3-methy-4-nitroctechol (3M4NC) compound.

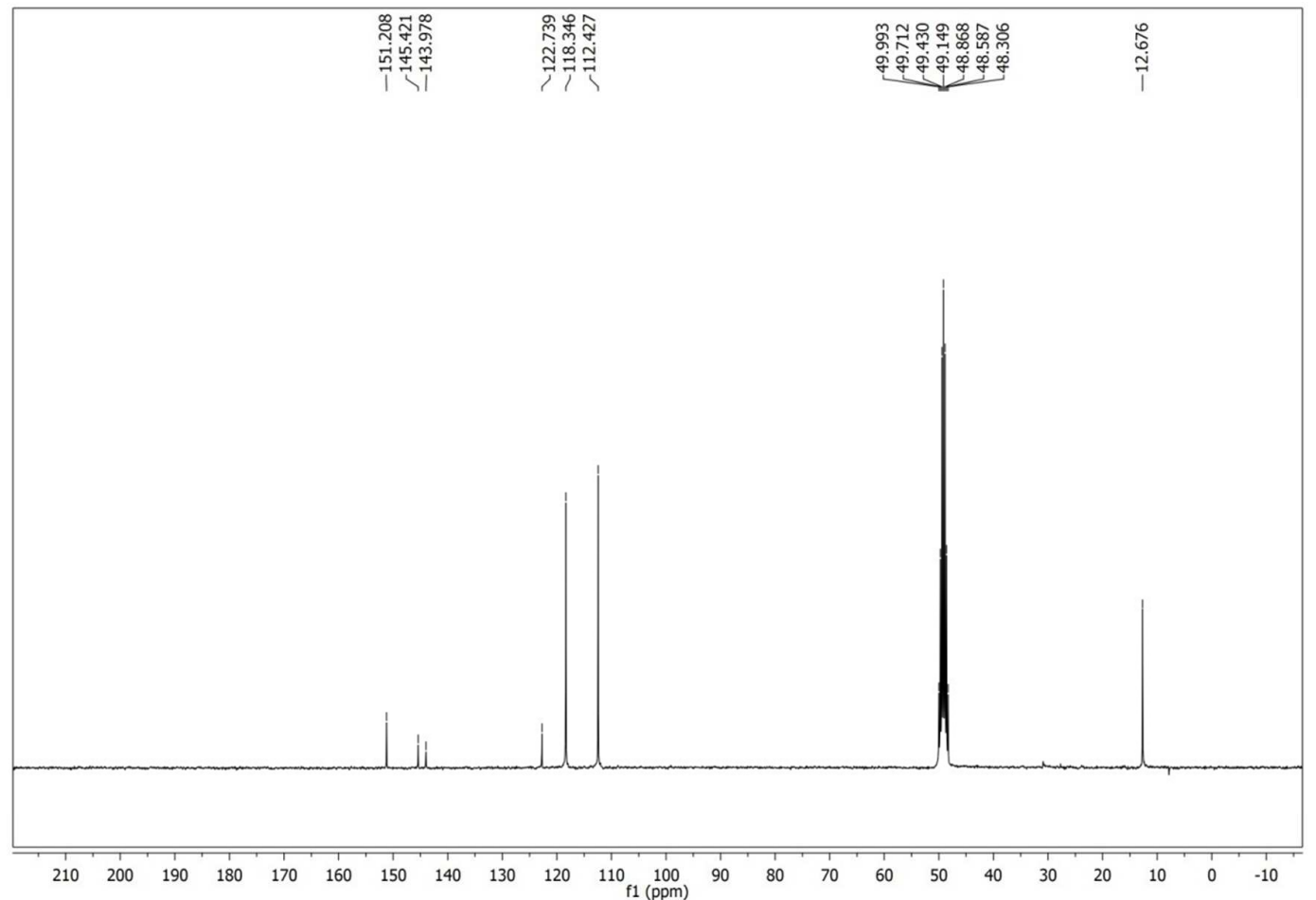

Figure S3. ${ }^{13} \mathrm{C}-\mathrm{NMR}$ spectrum of 3-methy-4-nitroctechol (3M4NC) compound. 


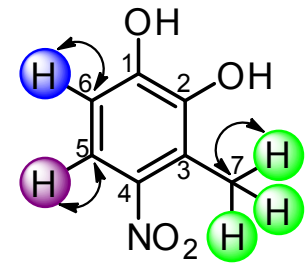

${ }^{1} \mathrm{H}-{ }^{13} \mathrm{C}$ gHSQC Correlation
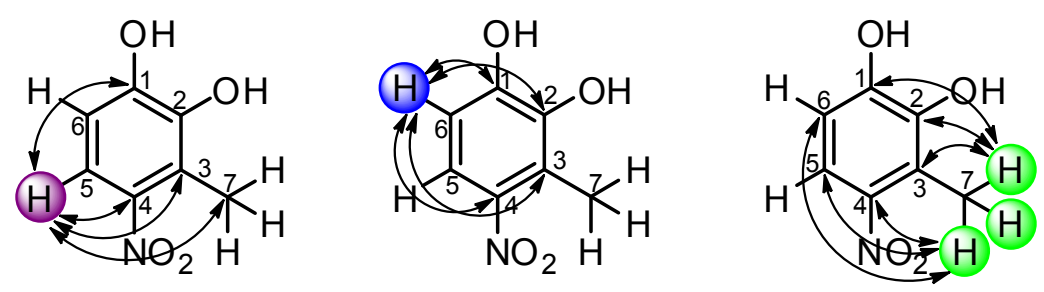

${ }^{1} \mathrm{H}-{ }^{13} \mathrm{C}$ g HMBC Correlation

Figure S4. gHSQC and gHMBC correlations for 3-methyl-4-nitrocatechol (3M4NC).

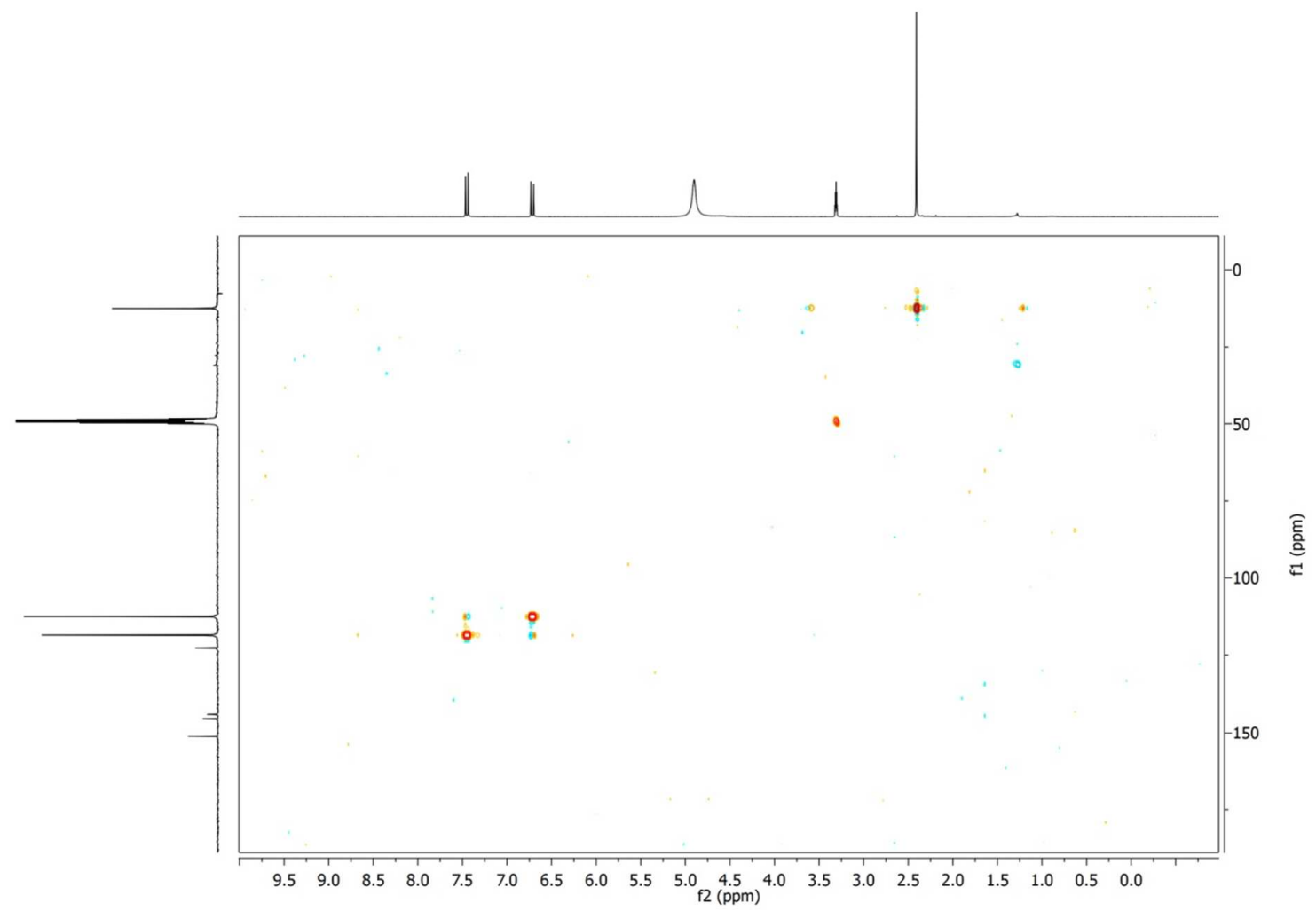

Figure S5. 2D contour plot of heteronuclear $\left({ }^{1} \mathrm{H}-{ }^{13} \mathrm{C}\right)$ correlations from $2 \mathrm{D}-\mathrm{NMR}$ gHSQC experiments. 


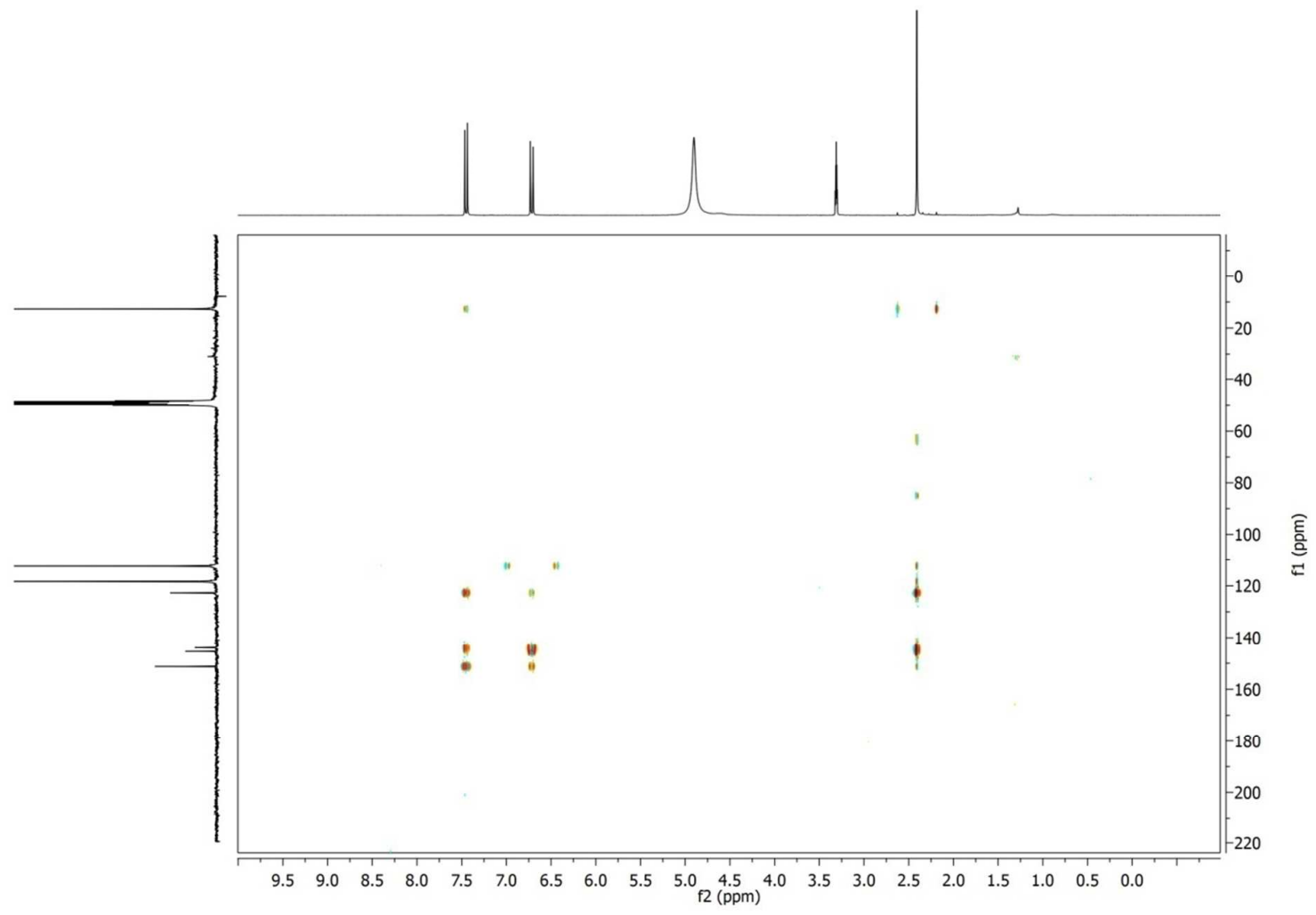

Figure S6. $2 \mathrm{D}$ contour plot of heteronuclear $\left({ }^{1} \mathrm{H}_{-}{ }^{13} \mathrm{C}\right)$ correlations from $2 \mathrm{D}-\mathrm{NMR}$ gHMBC experiments. 
Table S3. NMR data and ${ }^{13} \mathrm{C}-\mathrm{NMR}$ predictions of 3-methyl-4-nitrocatechol (3M4NC) in $\mathrm{CD}_{3} \mathrm{OD}$.

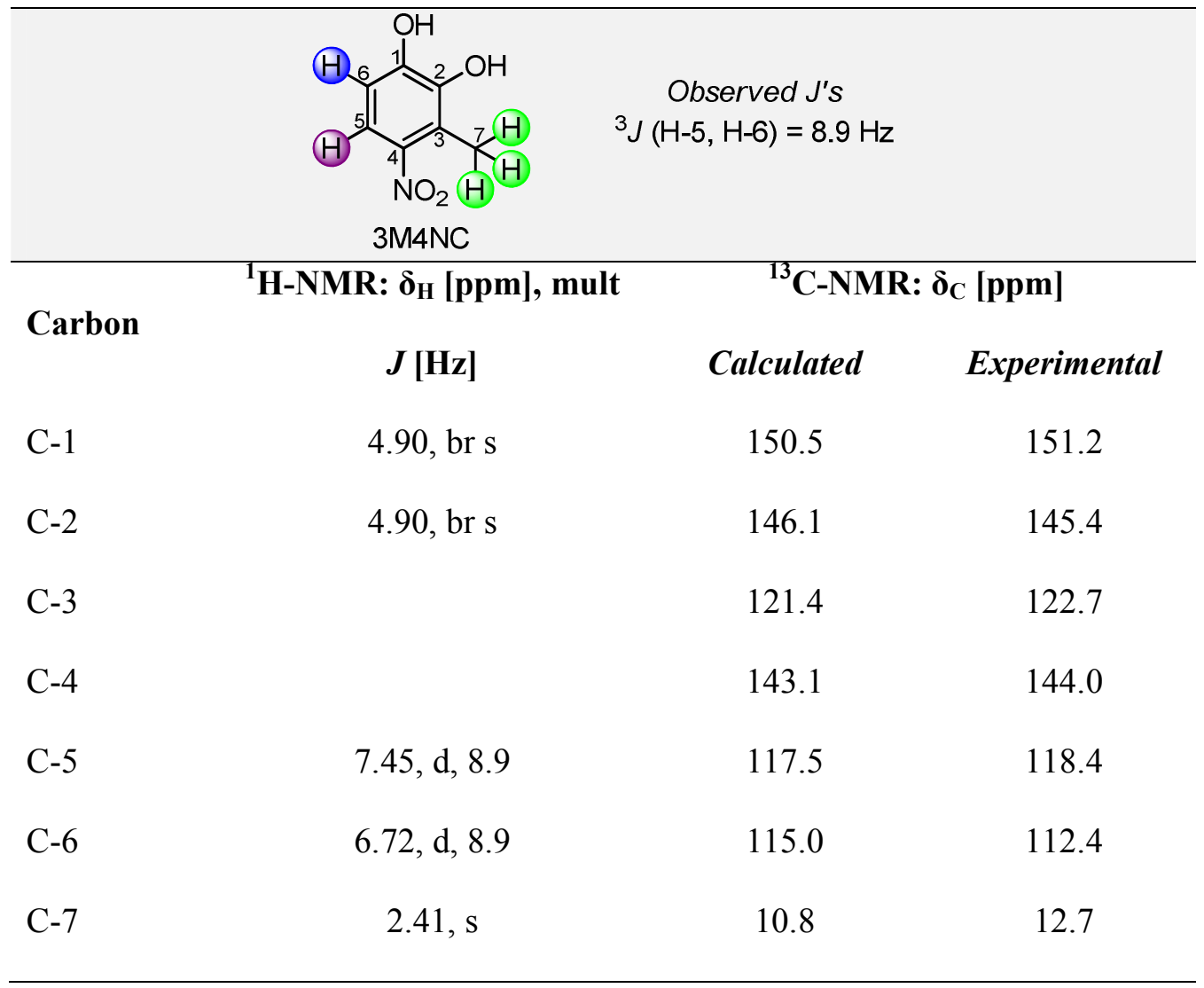


Table S4. Concentrations of methylnitrocatechols determined in $\mathrm{PM}_{2}$ samples $(n=7)$ collected during winter 2014/2015 from Ljubljana, Slovenia.

\begin{tabular}{|c|c|c|}
\hline \multirow{2}{*}{ Analyte } & \multicolumn{2}{|c|}{ Aerosol concentration $\left(\mathrm{ng} \mathrm{m}^{-3}\right)$} \\
\hline & average & range \\
\hline $4 \mathrm{M} 5 \mathrm{NC}$ & 15.0 & $8.9-25.4$ \\
\hline $3 \mathrm{M} 5 \mathrm{NC}$ & 23.7 & $10.2-43.2$ \\
\hline 3M4NC & 4.1 & $2.0-8.2$ \\
\hline$\Sigma M N C$ & 42.8 & $23.1-75.6$ \\
\hline $\mathbf{P M}_{2} \operatorname{mass}\left(\mu \mathrm{g} \mathrm{m}^{-3}\right)$ & 28.45 & $15.88-53.44$ \\
\hline
\end{tabular}

\section{References}

1. Iinuma, Y.; Boege, O.; Graefe, R.; Herrmann, H., Methyl-Nitrocatechols: Atmospheric Tracer Compounds for Biomass Burning Secondary Organic Aerosols. Environ. Sci. Technol. 2010, 44, (22), 8453-8459.

2. Kitanovski, Z.; Grgić, I.; Yasmeen, F.; Claeys, M.; Čusak, A., Development of a liquid chromatographic method based on ultraviolet-visible and electrospray ionization mass spectrometric detection for the identification of nitrocatechols and related tracers in biomass burning atmospheric organic aerosol. Rap. Comm. Mass Spec. 2012, 26, (7), 793-804. 